\title{
Some Aspects of Burnout in Nursing Homes
}

\section{Ljiljana Leskovic - Goran Vukovič - Robert Leskovar - Jana Goriup*}

\begin{abstract}
Nursing personnel in nursing homes for elderly citizens are exposed to a number of factors that contribute to possible burnout syndrome. For this reason, the set objective of the research was to measure the degree of burnout, check the correlation between the burnout syndrome and satisfaction at work, and psychosomatic symptoms, as well as to figure out the main characteristics of burnout syndrome among the nursing personnel in nursing homes for the elderly in Slovenia.
\end{abstract}

Key words: burnout, work satisfaction, psychosomatic symptoms, nursing homes for the elderly, nurses.

\section{Introduction}

Nowadays, for the burnout syndrome there is still no standard definition, despite the fact that a great deal has been written about what it is and what can be done in relation to it. A few definitions, which occur more frequently than others can be found in the literature. The care is loaded with many working conditions, which create a good basis for the development of burnout: too much work, a constant concern, high responsibility, low level of decision-making, lack of awards, inappropriate technology, low salary and shift work (Goriup \& Purgaj, 2009; Leskovic \& Leskovar, 2014). In contrast to nursing personnel in other institutions, nurses in homes for the elderly accompany their patients for many years, mostly until their death. Nursing care of people with dementia often brings about a qualitatively and quantitatively overload of the personnel due to high work requirements, functional and behavioural dilution of a patient and the ethical dilemmas raised by the difficulties of interpretation when it comes to elderly people, especially in the long-term residence situations, where specifics are immense. What is more, care of patients with dementia requires a lot of

Ljiljana Leskovic, Faculty of Health Sciences Novo mesto, Novo mesto, Slovenia; ljiljana.leskovic@guest.arnes.si

Goran Vukovič, Faculty of Organizational Sciences, University of Maribor, Maribor Slovenia; goran.vukovic@fov.uni-mb.si

Robert Leskovar, Faculty of Organizational Sciences, University of Maribor, Maribor Slovenia; robert.leskovar@fov.uni-mb.si

Jana Goriup, Faculty of Health Science, University of Maribor, Maribor, Slovenia; jana.goriup@guest.um.si 


\section{Acta Technologica Dubnicae \\ volume 6, 2016, issue 2}

emotionally involved work of the nurses. Therefore, nurses are experiencing a higher pressure at work. Although some of the personnel are able to resolve the feelings, excited by such work, and thus maintain the empathy, some nurses, however, develop symptoms of exhaustion, feelings of low self-esteem, failure and helplessness. Carers of people with dementia are daily exposed to ethical conflicts, since it is difficult to interpret all of the patients' wishes. Thus, the carer is often required to act in the name of patient, which can lead to double blind conflicts and exhaustion of the carer. Precisely the complex situations faced by nurses, and their close connection with the patients, enable us to talk about the possibilities of the burnout syndrome occurrence, not only about overload at the workplace. Selič (2010) points out that burnout is a sign of an exhausted and defective bio-psycho-social well-being, which can lead to absenteeism or leaving the profession. Glasberg (2007) indicates in a study about burnout among health care workers, that the health care reorganization is causing a structural instability, more conflicts and unclear responsibilities, all of which contribute to an increase in numbers of days on sick leave caused by symptoms of burnout. Åström (1990) found in his study, conducted in Sweden, that of all the nurses who work with the elderly, approximately 25 percent have a high estimation of burnout and approximately 35 percent of them had already been at risk of developing the burnout syndrome. Among the nurses, who were willing to change their jobs, 27 percent were at risk of developing the burnout syndrome. Among those, who would not change their profession, the share was lower, namely $16 \%$.

\section{Healthcare demands a rethink of education}

Filej (2001, p. 72) is convinced that nursing is based on education, knowledge and techniques derived from humanistic and natural sciences; as a discipline the primary and fundamental task of which is "to care for people". Therefore, nursing is a science of how to help and care for people in a state of health and disease at the time of independence and when assistance in carrying out basic life activities is needed. A nurse is a person who keeps, brings up and protects the other. She is ready to care for sick, injured and elderly people.

As nursing is one of the most highly health professions in European Union, and a license is required to practice in all 28 States, also in Slovenia, and due to the rapid development of the health sector and the requirements and needs of the society for knowledge in the healthcare field an adequately qualified and trained practitioner of nursing is expected, who during tertiary education obtains relevant competencies for an effective implementation of health care (Bezenšek, 2007 , p. 217). 


\section{Acta Technologica Dubnicae \\ volume 6, 2016, issue 2}

Health care in contemporary Slovenia is provided by a myriad of professional groups, separated educated. Ideally, a team working has the patient at its centre and nurses, doctors, therapists, radiographers and laboratory scientific officers all working together and sharing information on the patient. Equally, the primary includes general practitioners, midwives and community nurses liaising with pharmacists. Especially the relationship between nurses and doctors has been affected by changes in the old dichotomy of nursing as care and medicine as treatment. The educational professionalization strategies of nurses have challenged the role boundaries between nurses and doctors and nurses take on prescribing and treatment roles, as the demand for nurses to take on some (before) doctor roles, have increased. These trends show how inter- and intrarelations in health care are becoming more complex, but also might be understood as simplistic. Often, however, the reality behind this idealized sense of harmony and cooperation is one of subtle hierarchies, poor communication and misunderstanding. There are tensions and disputes within and between them, in addition and change from a variety of different sources including the public, the media and government, as well. All are facing constant conflicts (the battle for authority between nurses and doctors etc.), challenges which often lead to burn out. Certainly, there are deep-seated anxieties about the collapse of trust between them.

Modern nursing demands a rethink of educational goals and skills for a successful professional health management and the according education system. In Slovenia education for nurses is organized in faculties for health care and nursing, with an undergraduate study programme adjusted to the European directives for regulated profession. Currently, the undergraduate study programme Nursing level I, which is adjusted to the Bologna Declaration, as well as post-graduate study programmes i.e. the post-graduated study programme in Nursing, the post - graduate study programme in Bioinformatics and the higher education study programme Nursing - level I (Bologna program) and the post - graduate study programme Management in health and social care are being performed. The educational programme graduates distinguish themselves in their professional attitude towards work, interdisciplinary knowledge, ability to communicate effectively, broad education, self- reflection, the ability of quick and correct decision-making, heart and culture and their sentient and ethical attitude towards the patient and elderly, as well as other users of their services, the ability of teamwork and work in international teams and projects. Thus, in their professional work, students and especially graduates are guided by the following principles, that: people are always the most important; relationships are based on honesty; the diversity of people and ideas are welcome; conflicts are a creative source of new ideas; discussions are held on an academic level; excellence is realized through teamwork; commitment to intellectual achievement is highly valued. 


\section{Acta Technologica Dubnicae \\ volume 6, 2016, issue 2}

Access to healthcare education involves a highly competitive selection process. This process in itself can be seen as the first step towards professional socialization. Once entry to nursing school is secured, education involves not only the transfer of knowledge but also the absorption of appropriate attitudes and behaviour towards patients and colleagues. In this sense, the nurse profession has, within its training process, a built-in capacity to mould new members in its own image. Studies of nurse education have shown how this capacity is maintained through the formal educational curriculum, which passes on knowledge and skills and involves periodic formal assessment, and the informal curriculum, which transmits attitudes, behaviours and beliefs and where the assessment is based on the approval of performed roles. This procedure gradually built up to style of doing things that are accepted and seen as "professional". This profession is a great challenge and can be handled only by nurses with a deliberately planned system of educational activities, applying diverse methods, forms and means; those who act as actual authorities by their personal example, gestures and words. The nurse should act as a personality in every situation, be a good example and a coordinator of professional influences; she should be able to act assertively and argument professionally and not be manipulated by anyone. The nurse should be self-disciplined, enthusiastic, sincere and self-reflexive, if needed. She should not fall prey to scepticism and despair.

However, the Slovenian concept of health education is still connected with the conviction that the doctor is the only one able to manage the whole medical organization. The classical principal has its roots in the idea that the basic education for nurses is mainly practical oriented and managers in healthcare are supposed to think they have to take control of the staff and lead them to objective economic aims, not to support the role of education for nurses. This kind of leading has negative effects on the professional work of nurses. Thus, managers should support and lead their staff at work. Medical employees are supposed to find their own way to exceed the stereotypical education of nurses and their work. They work in a team, considering values of the organization, interests and wishes of patients, working in co-operation with their colleagues. At work, nurses, according to modern education skills and their competences, are self-confidential and have their own vision, knowing other alternatives. They know how to differ the good and the bad ethically. But sometimes, they expose the situation of crises.

How can we understand this sense of crises among nurses? Rather, their professional relationships can be better understood by the concept of "countervailing powers", as work relations in health care are characterized as "a series of moves" between nurses and others involved, especially important 


\section{Acta Technologica Dubnicae \\ volume 6, 2016, issue 2}

nowadays in this increasingly uncertain world. Most important characteristics of nurse profession are:

- discrete body of knowledge over which nurses have control,

- non autonomy over conditions of work and from state and capital,

- monopoly over health market for services,

- code of ethics,

- strong sense of altruism is a core motive and performance is valued

- more than financial reward,

- training is lengthy and its quality and content is determined by the nurses themselves,

- contradictions within assumed value systems.

During their professional career, nurses must deal with more or less serious problems, intrapersonal and interpersonal conflicts, stressful situations, and other adverse circumstances, risk factors that can negatively influence one's healthy development. They increase the probability of negative developmental outcomes and problem behaviours. As under their influence one's reactions are often unusual, not relevant to the given situation, we drew an important distinction between professional autonomy and professional dominance, as nurse's professional power is based on her education and competences, autonomy over her own work and dominance over activities of co-workers, coping with different forms of autonomy in her professional formation (clinical, economic, social and political autonomy). So qualities such as nurse professional ethics, knowledge, monopoly, and authority over patients and autonomy over her work are seen to be very important in the face of public.

All these facts allow educational goals about their work to emerge. In order to allow the development of the health system, healthcare should not be understood as a system of isolated components. In health organizations people form the system. Here, individuals and groups meet, having different opinions, convictions and thinking. They all have their own system of values, needs and interests. A health organization is successful and effective only if an individual group faces the permanent need for education, but the most important is the cooperation between all elements.

\section{Nurses in nursing homes}

The consequences of population aging are numerous, both economic as well as social, but they are most evident in the field of labour and healthcare system, as well. Postmodern society increasingly tends to exclude the elderly, it treats them as incompetent for independent living. Therefore, the tendency to put them into nursing homes is increasing, where they cope with nurses which are overworked, 


\section{Acta Technologica Dubnicae \\ volume 6, 2016, issue 2}

tired and burn out. And mostly not enough educated for intergenerational cooperation, as working with elderly requires thoughtful planning, understanding their needs and (mostly) health problems, what led to different ethical and legal dilemmas. Nurses working in nursing homes take different responsibilities that cannot be defined only by law and regulations. In addition, nurses should protect and respect not only the elderly's health but also their privacy. But are they educated enough as their work with elderly has become an increasing challenge as the demands of elderly are rapidly evolving and become more complex and diverse?

Carrying out the work of a nurse in nursing home, besides high professionalism and self-control also takes respect for moral principles. Ethical behaviour presupposes the respect for the self, for elderly, empathy and the ability to take into consideration interests and needs of the elderly when making a decision. A professional ethical approach of a nurse means to apply general moral principles. Therefore, the education should prepare nurses to master: verbal communication, principles of conflict-free communication and principles of good manners, the ability to gain confidence of the sick, closely follow the standards, be confident about their work, be willing to study permanently and have a sense of justice. And, last but not least, to create her professional authority.

\section{Methodology}

Our research involved 98 participants, all working in the position of a nursing assistant in nursing homes for the elderly citizens in Slovenia. More specifically, an average of 10 respondents from each home for the elderly participated in the research, and the selection of participating nursing homes was random. Participation was voluntary and anonymous.

\subsection{Sample}

There were 97 women and only one man among the respondents. Their average age was 38 years, the youngest participant was 20 years old, and the oldest was 53 years old.

\subsection{Instrumentation}

For collection of data we used a questionnaire about the burnout syndrome, a questionnaire to measure satisfaction at work, a check list of psychosomatic disorders, structured interview and a socio-demographic questionnaire.

\subsubsection{Measuring the burnout}

The used questionnaire about the burnout was the C. Maslach - MBI (Maslach \& Jackson, 1979, Penko, 1994), which enabled us to measure the rate of burnout. The questionnaire's measurement characteristics were often tested, and it 


\section{Acta Technologica Dubnicae \\ volume 6, 2016, issue 2}

measures the three aspects of burnout: emotional exhaustion, depersonalization and personal fulfilment. It is composed of two parts, the first part is measuring frequency, and the second part is measuring the intensity of individual subscales.

Each part of the questionnaire contains 22 items which are measured on both dimensions (frequency and intensity) by using the two Likert-type scales. The frequency of occurrence is estimated from the value 1 , which indicates a rare observation phenomena (a few times per year), up to the value 6 , which indicates an often observation phenomena (every day). The intensity is enumerated from the value 1 , which means a very poor experience, up to the value 7 , which means a very strong experience. In both cases, the value 0 can be chosen, if the state has never been experienced.

For each of these two parts of the questionnaire, the points are calculated for each subscale separately. Thus the obtained total points represent results in six subscales, indicating frequency and intensity of emotional exhaustion, depersonalisation and personal fulfilment. Higher is the number of points on each of the subscales, the greater is the emotional exhaustion, depersonalization and personal fulfilment. The burnout is indicated by the higher emotional exhaustion and depersonalisation and smaller personal fulfilment.

\subsubsection{Measurement of satisfaction at work}

The satisfaction at work has been measured with the adaptation of an American questionnaire, known as the Job Descriptive Index, shorter JDI (Smith, Kendall and Hulin, 1969, Konrad, 1994). The questionnaire measures satisfaction with five aspects of work, namely: the work itself, co-workers, direct managers, salary and promotion. It contains 106 items altogether, for each the participant assesses whether it is applicable to their situation and answers with yes, no or I do not know. Approximately half of the items have a positive valence, and the other half has a negative one. The questionnaire points are calculated as follows: items with the positive connotation, answered with a yes, are attributed three points, the I do not know answer gets one point and the answer no gets no points. For items with a negative connotation, the response no is attributed three points, the I do not know answer gets one point and the answer yes does not get any points. Points are calculated separately for each aspect of satisfaction and thus we obtain five scores (Konrad, 1994). Using the computer program JDI.EXE, where we enter the raw data, it calculates how many points an individual has achieved in the individual aspect and factor and in which category of satisfaction the result belongs to (Sabadin, 2000). 


\section{Acta Technologica Dubnicae \\ volume 6, 2016, issue 2}

\subsubsection{Measuring psychosomatic symptoms}

The frequency and intensity of the psychosomatic symptoms were measured by using the check list of psychosomatic symptoms, made for the purpose of research, based on the Engel's classification of psychosomatic disorders (1967, in Luban-Plozza et al., 1993). The check list consists of 11 groups of problems and diseases, where some groups have also been added some of the more common psychosomatic diseases.

\subsubsection{Data collection process}

The research was conducted in 2010 in ten Slovenian homes for the elderly citizens. First of all, the request for cooperation was addressed to the directors of the homes for the elderly. Upon the approved request, we started the contact the head of the nursing care in each home. The purpose of cooperation was explained to each of the participant, as well as we informed them that participation in the research was on a completely voluntary basis and that the data will be processed only collectively. With those who gave their consent for participating, we performed an individual interview, which took place in one of the premises of the home for the elderly, where the participant was employed. In the final part of the interview the check list of psychosomatic disorders was included as well. Each interview lasted approximately for half an hour. The participants were also asked to complete two more questionnaires at home, and answer some socio-demographic questions. After a few days, they returned the forms and questionnaires to the head of nursing care, who forwarded them to us. Of the 150 distributed questionnaires, 98 were returned and suitable for further processing.

\subsubsection{Statistical Analysis}

The collected data were processed in the SPSS 18.0 program. The only exception were the data from the questionnaire about the job satisfaction at work - JDI, which were processed and evaluated using the program JDI.EXE. We used the following statistical analyses:

- for description of the sample and displaying results from the questionnaires and the interview, we used descriptive method, the normal distribution was checked with the Kolmogov-Smirnov test;

- for verifying the correlation between different variables, we used the Spearman's correlation coefficient.

- the differences between the arithmetic mean values of the individual variables were examined with t-test and the analysis of variance. 


\section{Results}

\subsection{The Burnout syndrome}

Table 1

The number of participants according to the individual phase of frequency and intensity

Burnout according to the 8-phases model $(N=98)$

\begin{tabular}{lllllllll}
\hline & \multicolumn{1}{c}{ phases of burnout } \\
\cline { 2 - 9 } & I & II & III & IV & V & VI & VII & VIII \\
\hline frequency of burnout & 34 & 0 & 17 & 0 & 45 & 1 & 1 & 0 \\
intensity of burnout & 29 & 0 & 7 & 0 & 59 & 2 & 1 & 0 \\
\hline
\end{tabular}

It is evident form table1 that according to the frequency of burnout, one third of participants were placed into the first phase of burnout, less than a fifth in the third phase, and half of the participants were placed into the fifth phase of burnout. According to the intensity of burnout, most participants (59) were placed into fifth phase, a little less (29) were recognized in the first phase of burnout. The third, sixth and seventh category were in both cases of burnout more poorly represented, and none of the participants were placed into the second, fourth and eighth phase.

Table 2

Descriptive Statistics of indexes and dimensions of burnout in terms of frequency and intensity $(N=98)$

\begin{tabular}{lcccc}
\hline & $M^{a}$ & $S D^{b}$ & asymmetry & kurtosis \\
\hline frequency & & & & \\
index of burnout frequency & 2.37 & 1.04 & -0.21 & -0.99 \\
emotional exhaustion & 3.32 & 1.18 & 0.23 & -0.93 \\
personal fulfillment & 4.24 & 1.14 & -0.72 & -0.22 \\
depersonalization & 1.40 & 1.03 & 1.07 & 2.00 \\
intensity & & & & \\
index of burnout intensity & 2.42 & 1.07 & -0.14 & -0.66 \\
emotional exhaustion & 2.72 & 1.57 & 0.50 & -0.33 \\
personal fulfillment & 4.38 & 1.29 & -0.44 & 0.40 \\
depersonalisation & 1.67 & 1.09 & 0.40 & -0.60 \\
\hline
\end{tabular}

Notes. Standard error in the asymmetry test was 0.34 in all cases, in the kurtosis test it was 0.67. $\mathrm{a,b}$ - the average scale ratings and their standard deviation due to a different number of items in the various scales were calculated; the average rate may vary between 0 and 6 in terms of frequency and between 0 and 7 regarding intensity. 


\section{Acta Technologica Dubnicae \\ volume 6, 2016, issue 2}

It can be seen from table 2 that the participants have chosen the highest ratings, both in terms of frequency as in terms of the intensity, at the personal fulfilment dimension, and the lowest ratings at the dimension of depersonalisation. In this respect, it is worthwhile to note that a high level of burnout is defined by the high results in the dimensions of emotional exhaustion and depersonalisation and the low results in the dimensions of personal fulfilment. On all dimensions of intensity, the arithmetic mean values are slightly higher, which is most likely due to one multi-stage scale assessment as with frequency. Between the two indexes of burnout there are no major differences, not with the arithmetic mean value, nor with the standard deviation value. A left asymmetry in the dimension of depersonalisation in terms of frequency can be seen, however, the Kolmogorov-Smirnov test $(\mathrm{Z}=0.73, \mathrm{p}<0.66)$ shows that the distribution of the mentioned variable does not much differ from the normal distribution. As for the other dimensions and both indexes of burnout, the Kolmogorov-Smirnov test does not show significant deviations from the normal distribution. We were also checking the internal consistency of the MBI questionnaire and its dimensions. The reliability coefficients were relatively high, the Cronbach's alpha for the entire scale of the burnout frequency was 0.77 , and for the intensity scale it amounted to 0.85 .

\subsection{Satisfaction with work}

The descriptive statistics enabled us to find out that participants were choosing the lowest grades when enumerating their satisfaction with the personal income, the highest grades, however, were assigned to satisfaction with the head nurse and co-workers.

Similarly, the review of the factors of satisfaction reveals that the lowest grades are observed at the satisfaction with personal income, and the highest average assessment grades are assigned for the satisfaction with the head nurse and coworkers. Furthermore, from five aspects of the satisfaction category, we calculated the average category of satisfaction with work for each participant. The average varied between 1.60 and 4.60, their average was 3.09 , SD was 0.82 . 


\section{Acta Technologica Dubnicae \\ volume 6, 2016, issue 2}

Table 3

Spearman's correlation coefficient between dimensions and indexes of burnout, and aspects and factors of satisfaction with work $(N=98)$

\begin{tabular}{|c|c|c|c|c|c|c|c|c|}
\hline \multirow[b]{2}{*}{ JDI } & \multicolumn{4}{|c|}{ frequency of burnout } & \multicolumn{4}{|c|}{ intensity of burnout } \\
\hline & či & oi & $\mathrm{d}$ & ipi & či & oi & $\mathrm{d}$ & iii \\
\hline \multicolumn{9}{|l|}{ aspects } \\
\hline del & -0.11 & 0.23 & 0.02 & -0.13 & -0.25 & 0.18 & -0.27 & -0.26 \\
\hline vod & -0.17 & 0.17 & -0.07 & -0.20 & -0.27 & 0.09 & -0.15 & -0.26 \\
\hline sod & 0.06 & 0.22 & 0.06 & -0.04 & -0.01 & 0.15 & 0.06 & -0.07 \\
\hline doh & $-0.32 *$ & 0.38* & -0.21 & $-0.41 *$ & -0.28 & 0.25 & -0.18 & $-0.37 *$ \\
\hline nap & -0.05 & 0.02 & -0.07 & -0.04 & -0.21 & 0.11 & -0.15 & -0.22 \\
\hline zad & -0.14 & 0.28 & -0.08 & -0.21 & -0.26 & 0.24 & -0.15 & $-0.29 *$ \\
\hline kzad & -0.13 & 0.27 & -0.06 & -0.19 & -0.27 & 0.21 & -0.18 & $-0.32 *$ \\
\hline \multicolumn{9}{|l|}{ factors } \\
\hline f1 & -0.19 & 0.26 & -0.10 & -0.24 & -0.26 & 0.18 & -0.08 & -0.26 \\
\hline $\mathrm{f} 2$ & 0.01 & 0.22 & 0.05 & -0.08 & -0.06 & 0.14 & 0.06 & -0.10 \\
\hline f3 & $-0.37 *$ & $0.41 *$ & -0.23 & $-0.47 *$ & $-0.34 *$ & 0.25 & -0.20 & $-0.42 *$ \\
\hline $\mathrm{f} 4$ & -0.14 & 0.08 & -0.10 & -0.13 & -0.28 & 0.14 & -0.17 & -0.29 \\
\hline f5 & 0.02 & 0.27 & 0.06 & -0.04 & -0.10 & 0.25 & -0.15 & -0.16 \\
\hline f6 & $-0.33 *$ & -0.08 & -0.08 & -0.20 & $-0.40 *$ & -0.08 & $-0.31 *$ & -0.28 \\
\hline $\mathrm{f} 7$ & 0.02 & 0.05 & 0.05 & -0.06 & -0.07 & 0.01 & -0.13 & -0.07 \\
\hline f8 & -0.22 & 0.22 & -0.07 & -0.22 & -0.27 & 0.17 & -0.12 & $-0.25 *$ \\
\hline
\end{tabular}

Notes. *-correlation is statistically significant at the 0.05 risk level; **-correlation is statistically significant at the 0.01 risk level;

či - emotional exhaustion; oi - personal fulfilment; $d$ - depersonalization; ipi - the index of burnout frequency; iii - the index of burnout intensity; del — satisfaction with work; vod satisfaction with the head nurse; sod - satisfaction with co-workers; doh - satisfaction with personal income; nad - satisfaction with the possibility of promotion; zad - total satisfaction in the workplace; kzad - the average category of satisfaction with work; f1 - satisfaction with the head nurse; f2 - satisfaction with co-workers; $\mathrm{f} 3$ - satisfaction with personal income; f4 - satisfaction with the possibility of promotion; f5 - satisfaction with work; f6 - the absence of the stress effects of work; $f 7$ - absence of the sense of work alienation; f9 - the absence of negative personality traits of the head nurse.

The correlation between the personal income satisfaction and the frequency of emotional exhaustion, and burnout indexes was proven statistically significant. More specifically, it is a negative correlation, which means that more than a person suffers from burnout, the smaller is their satisfaction. Satisfaction with personal income is also significant correlating with the frequency of personal fulfilment, in which case there is a positive correlation. Frequent and intense emotional exhaustion and more intense depersonalisation, are negatively associated with the sixth factor, which refers to the absence of the stress effects 


\section{Acta Technologica Dubnicae \\ volume 6, 2016, issue 2}

of work. The latter means that the participants, who more often and more intensively experience emotional exhaustion and those who experience more intensive depersonalisation, perceive more stress effects of work and vice versa.

\subsection{Psychosomatic symptoms}

Table 4

Descriptive statistics and the results of Kolmogorov-Smirnov test for the Check list of psychosomatic symptoms scales for the past, as well as for the last 12 months $(N=98)$

\begin{tabular}{lllllll}
\hline & $M$ & $S D$ & asymmetry & kurtosis & $Z$ & $p$ \\
\hline in the past & 15.58 & 9.36 & 0.75 & -0.26 & 0.90 & 0.39 \\
the last 12 months & 15.40 & 10.03 & 0.69 & -0.54 & 1.02 & 0.18 \\
\hline
\end{tabular}

Notes. Standard error in the asymmetry test was 0.34 in all cases, in the kurtosis test it was 0.66 .

We can see in table 4 that both scales of psychosomatic symptoms have similar arithmetic mean and dispersion. The distribution of both scales does not differ statistically significant from the normal distribution, what is shown by the results of Kolmogorov-Smirnov test. Spearman's correlation coefficient between the scales amounts to 0.84 and is statistically significant $(\mathrm{p}<0,01)$. Cronbach's alpha of the check list equals 0.95 .

\subsection{The Burnout syndrome in correlation with psychosomatic symptoms}

Table 5

Spearman's correlation coefficients between the dimensions and indexes of burnout and psychosomatic dimensions and symptoms $(N=98)$

\begin{tabular}{|c|c|c|}
\hline \multirow[b]{2}{*}{ burnout } & \multicolumn{2}{|c|}{ psychosomatic symptoms } \\
\hline & in the past & in the last 12 months \\
\hline \multicolumn{3}{|l|}{ frequency } \\
\hline index of burnout frequency & $0.37 * *$ & $0.37 *$ \\
\hline emotional exhaustion & $0.44 * *$ & $0.47 * *$ \\
\hline personal fulfilment & -0.04 & 0.00 \\
\hline depersonalisation & 0.28 & 0.23 \\
\hline \multicolumn{3}{|l|}{ intensity } \\
\hline index of burnout frequency & $0.39 * *$ & $0.29 *$ \\
\hline emotional exhaustion & $0.46 * *$ & $0.39 * *$ \\
\hline personal fulfilment & -0.16 & -0.11 \\
\hline depersonalisation & 0.11 & -0.01 \\
\hline
\end{tabular}




\section{Acta Technologica Dubnicae \\ volume 6, 2016, issue 2}

\section{Discussion}

We have found out that, depending on the frequency of burnout in the participants, a third of them was classified into the first burnout phase, less than a fifth into the third phase and a half of the participants into the fifth phase of the burnout. According to the intensity of the burnout, most participants (59) were classified into the fifth stage, a little less (29) into the first phase of burnout. Both in terms of frequency as in terms of the intensity, the choice of the highest grades was for the dimension of personal fulfilment, the lowest grades were enumerated for the dimension of depersonalisation. In this respect, it is worthwhile to note that a high level of burnout is defined by the high results in the dimensions of emotional exhaustion and depersonalisation and the low results in the dimensions of personal fulfilment. On all dimensions of intensity, the arithmetic mean values are slightly higher, which is most likely due to one multi-stage scale assessment as opposed to the frequency. There are no major differences between the two indexes of burnout, not in the values of arithmetic mean, not in the standard deviation. A left asymmetry in the dimension of depersonalisation in terms of frequency can be seen, however, the KolmogorovSmirnov test $(\mathrm{Z}=0.73, \mathrm{p}<0.66)$ shows that the distribution of the mentioned variable does not statistically differ much from the normal distribution. As for the other dimensions and both indexes of burnout, the Kolmogorov-Smirnov test does not show significant deviations from the normal distribution. We were also checking the internal consistency of the MBI questionnaire and its dimensions. The reliability coefficients were relatively high, the Cronbach's alpha for the entire scale of the burnout frequency was 0.77 , and for the intensity scale it amounted to 0.85 .

We also confirmed that the correlation between the total satisfaction in the workplace and the average category of satisfaction at work is statistically significant and negatively connected with the intensity of experiencing burnout. This means that in the workplace more satisfied participants less intensively experience burnout and vice versa.

When checking the correlation with the Spearman's correlation coefficient, as statistically significant were proven the positive correlations between emotional exhaustion and psychosomatic symptoms (in both dimensions of burnout and in both scales of psychosomatic symptoms). What is more, in the past and in the last year, a positive and statistically significant correlation was proven between psychosomatic symptoms and both burnout indexes. The latter correlation is most likely the consequence of the emotional burnout, which takes a large part in the creation of the burnout index (4/7). The latter thesis can also be confirmed by a seemingly low and statistically insignificant correlation of psychosomatic symptoms with other dimensions of burnout (personal fulfilment 


\section{Acta Technologica Dubnicae \\ volume 6, 2016, issue 2}

and depersonalisation, both in the aspect of frequency, as well as the intensity). Since the personal fulfilment negatively contributes to the burnout syndrome, we would at this point expect a negative correlation between psychosomatic symptoms and emotional burnout, which was also generally shown (except in the case of personal fulfilment in terms of frequency and psychosomatic symptoms in the last year, where the connection is zero), however, these correlations are low and statistically insignificant.

The research focused exclusively on Slovenian homes for elderly people. After studying other researchers' work we could tentatively compare our study to the research done by Zeller, Hahn, Needham, Kok, Dassen and Halfens (2009), who found out that the most significant source of stress for the employees of elderly homes and visiting nurses is verbal violence from patients (threats, insults). Selič (2010) points out in her study that employees in primary medical care are burdened and Kržišnik and Čuk (2010) warn that the workers in psychiatric medical care experience stress while working with geriatric patients. The implication is that hospitals, nursing homes and homes for the elderly around the world experience similar problems to those in Slovenia, i.e. lack of staff, low levels of education and work-related stress (physical and psychological) which all contribute to the burnout phenomena. Our research was limited to ten homes but it could nonetheless be concluded that the problem of burnout is indeed present in all social welfare institutions and needs to be examined and studied seriously.

\section{Conclusions}

The above-mentioned, as well as many other things and elements influence the work of nurses on an unconscious level. This is also because their working place, from the economic and psychologic point of view, is a colder, inhospitable and much more demanding place than it used to be in the past. Often, nurses are exhausted emotionally, physically and mentally and they start to burn out, as their work, family and other obligations destroy their energy and devotion. Despite of being successful, they do not feel happiness and enthusiasm anymore. Their devotion to work decreases and they become cynical. The nurse's occupation with elderly exposes her to a broad range of physical and psycho-social insults.

This is the reason why they do their best in health care to be as less as possible personally involved in the problems of the elderly. Nurses are responsible for the preservation for the stereotypes, as certain stereotypes can be to their advantage or disadvantage. The research "Nurses in Slovenia", done by Klančnik Gruden (2000) at Ljubljana University Clinical Centre, revealed that nurses most often saw themselves as "working hands" and "kind-hearted", 


\section{Acta Technologica Dubnicae \\ volume 6, 2016, issue 2}

followed by the opinions "doctor's assistant" and "professional" on the third and fourth place. Nurses try to keep the status of a "good" nurse when being in contact with their patients, even if they do not always succeed due to too much work. They are convinced that for elderly their empathic relationship is more important than their professionality.

Nurses are very much aware of these problems and the restrictive government measures. This is the reason why they are trying to improve the importance of their function with elderly and in the health organization. We all are obliged to provide a rational relationship between service and its price. Due to this, nurses working with elderly are expected to be flexible and always available. Based on this, the economic logic interfered into the relationship between the elderly and the nurse which is immanent and their private one (Goriup, 2011, p. 845). Judging from the obtained results, it is urgent that the risk factors contributing to the burnout syndrome are recognised in time. Therefore, social welfare institutions need to start developing a process of evaluation of psychosocial and medical risk factors contributing to work stress, or face large financial losses due to stress-related sick leaves. On the other hand, institutions should provide moderate work demands, give their employees a chance to choose and control the work tasks they perform, reward them for good performance, strengthen coworker relationships, promote honesty, respectfulness and fairness, and most importantly, help employees to feel that what they do is meaningful and appreciated.

In order to be able to generalize the findings, we suggest that nurses working in nursing homes, avoiding burnout, should be as educated as possible, because this is the only way to provide a holistic and qualitative nursing care to elderly. Efforts should be made to raise the educational structure in this profession. Only the nurse's knowledge and her high professionalism will contribute to the improvement of the general health of the elderly, higher quality of their lives and the development of the society in general.

\section{References}

Abdul, S. A. (2000). Instructions for the evaluation of the questionnaire of satisfaction at work through the JDI. EXE (Unpublished material).

Bezenšek, J. (2007). Nekateri sociološki vidiki poklicne aktivnosti medicinske sestre. In V. Rajakovič (Ed.), Ustvarjalna organizacija-Zbornik povzetkov referatov (pp. 214 - 220). Portorož: FOV.

Filej, B. (2001). Profesionalna načela v zdravstveni negi. Obzor Zdr, 35, 71 74. 


\section{Acta Technologica Dubnicae \\ volume 6, 2016, issue 2}

Glasberg, A. L., Norberg, A., \& Söderberg, A. (2007). Sources of burnout Among Healthcare Employees as Perceived by managers. Journal of Advanced nursing, 60(1), 10-19.

Goriup, J., \& Purgaj, T. (2009). Nekateri sociološki vidiki razširjenosti mobinga med učitelji v osnovni šoli. Revija za elementarno izobraževanje, 2(4), 526.

Klančnik Gruden, M. (2003). Sociološki vidiki položaja in vloge medicinskih sester v Sloveniji, študija primera. Ljubljana: Fakulteta za socialno delo.

Leskovic, L., Leskovar, R., \& Vukovič, G. (2014). Interdisciplinary treatment of combustion phenomenon in nursing and care [Interdisciplinary analysis of nurse burnout]. Journal of Health Sciences, 1(2), 32-43.

Luban-Plozza, B., Pöldinger, W., \& Kröger, F. (1993). Psychosomatic patient at the general infirmary and its treatment FNAC in Slovenia. Ljubljana.

Selič, P. (2010). Stress and burnout: how is it possible to understand and apply information about Burnout on the primary level of health care. In B. Bregar \& J. Peterka Novak (Eds.), How to reduce stress and burnout in the workplace - Seminar section of the nurses and health technicians in Psychiatry. Ljubljana: Chamber of Commerce of medical and midwifery care Slovenia, Association of societies registered nurses, midwives and medical technicians, nurses and medical technicians Section in Psychiatry.

Maslach, C., \& Jackson, S. E. (1981). The measurement of experienced burnout. Journal of Occupational Behavior, 2, 99-113.

Morton-Cooper, A. (1984). The end of the rope. Nurs Miror, 159(21), 16.

International classification of diseases and related health problems for statistical purposes (ICD-10: the tenth revision ed.). (2005). IVZ. 2005

Kržišnik, K., \& Čuk, V. (2010). Load and combustion of health care staff in Psychiatry. In B. Bregar \& J. Peterka Novak (Eds.), How to reduce stress and burnout in the workplace - Seminar section of the nurses and health technicians in Psychiatry (pp. 38-40). Ljubljana: Chamber of Commerce of medical and midwifery care Slovenia, Association of societies registered nurses, midwives and medical technicians, nurses and medical technicians Section in Psychiatry.

Zeller, A, Hahn, S., Needham, I. et al., (2009). Aggressive behavior of nursing home residents toward caregivers: a systematic literature review. Geriatr Nurs, 30(3), 176-182. 